\title{
The role of linguistic context in children's interpretation and acquisition of Cicewa idiomatic expressions: A systemic functional linguistics approach
}

Mervis Kamanga and Felix Banda

\begin{abstract}
:
Research findings have shown that linguistic context helps young children to infer the figurative meaning of an idiom and learn the meaning. In this study, the role of linguistic context in children's interpretation and acquisition of idioms was tested in 20 Cicewaspeaking children aged 4, 6, 9, 12 and 14 years in three experiments. Experiment 1 tested children's ability to interpret idiomatic expressions in story context, Experiment 2 tested children's ability to interpret idiomatic expressions in sentence context and Experiment 3 tested children's ability to interpret idiomatic expressions out of context. The study adopted Systemic Functional Linguistics to establish the role of linguistic context in children's acquisition of Cicewa idioms. Our findings are: (1) Idioms are acquired as texts within the linguistic context in which they are produced and that linguistic context alone is not sufficient to facilitate idiom acquisition and interpretation. (2) Children come to know an idiomatic expression as a text before they understand the sociocultural context in which it is consumed. We argue that idioms are acquired as texts and they are acquired together with the sociocultural context in which they are produced and consumed, and therefore the sociocultural context forms part of the idioms.
\end{abstract}

\section{Introduction}

This research is in the area of child language acquisition, especially, acquisition of figurative language. Figurative language emphasises meaning by bringing 'an unclear concept alive' (Karuppali and Bhat 2013: 1), thereby, making communication effective. Among the common forms of figurative language in daily human communications are idioms. Idioms can be defined as expressions 'made up out of two or more words, at least one of which does not have any of the meanings it can have outside of the expression' (Riehemann 2001: 2). Although idioms are plentiful in every day human communication, it is not clear how people learn and understand idioms (Fazly, Cook and Stevenson 2009). Research findings on idiom acquisition are conflicting in many aspects. There are conflicting views and research findings regarding the age at which idiom acquisition starts. Some scholars like Prinz (1983) and Vulchanova, Vulchanov and Stankova (2011) propose that idiom acquisition starts between 6 and 7 years of age while others propose between 7 and 11 years of age (Levorato and Cacciari 1992; 1995). Research findings by Laval (2003) and 
Hsieh and Hsu (2010) indicate that at 6 years children are able to interpret idiomatic expressions. Vicker (2002) states that children below 6 can understand and use transparent idioms. This is in line with research findings by Gibbs $(1987 ; 1991)$ and Strand and Fraser (1979) who found that children as young as five years old can understand idioms. Schnell (2007) found that at around the age of four pragmatic competence emerges in children; hence they are able to handle non-literal expressions such as idioms.

There are also conflicting findings regarding the age at which children's knowledge of idiomatic expressions starts resembling that of adults. Some studies propose that age 10 is a turning point in idiom acquisition and the age at which children's idiomatic knowledge starts resembling the adult's knowledge (Vicker 2002; Vulchanova, Vulchanov and Stankova 2011; Ackerman 1982). Kempler, Lancker, Marchman and Bates (1999) provide evidence that children's idiomatic knowledge increases after the age 11 and it resembles the adult's knowledge. This means the 11-year-olds only interpret idioms figuratively. However, some research findings are not in support of this. The findings by Karuppali and Bhat (2013) showed that literal interpretation of idioms was dominant in 11-year-olds and that even fourteen-year-olds could not achieve 100\%. Furthermore, Lodge and Leach (1975) found that although twelve-year-olds understood some idioms, mastery of idioms is achieved at 20 years of age.

Research findings regarding the role of linguistic context in children's interpretation and acquisition of idioms are also inconsistent. It has been established that linguistic context plays a very crucial role in children's acquisition of idioms (Levorato and Cacciari 1995; 1999; Laval 2003; Hsieh and Hsu 2010; Leung 2011). It helps young children to infer the figurative meaning of an idiom and learn the meaning (Huber-Okrainee, Blaser and Dennis 2005). However, there are conflicting views regarding the age at which linguistic context starts to play a role in idiom interpretation and acquisition. Some scholars like Prinz (1983), Abkarian, Jones and West (1992), Levorato (1993) and Vulchanova, Vulchanov and Stankova (2011) propose that linguistic context has little or no effect on idiom understanding by children aged six years and below since they fail to use the information provided by the linguistic context to interpret idioms. Other scholars like Laval (2003), Hsieh and Hsu (2010) and Leung (2011) propose that linguistic context already starts to play an essential role in children's understanding of idiomatic expressions by the age six. Leung (2011) provides evidence that children aged six years avoided literal responses, and instead gave responses that were context dependent when idioms were presented to them within context.

All these conflicting views indicate that there is a problem in the way idiom acquisition has been approached. Although special attention has been paid to the role of linguistic context in idiom acquisition research, little attention has been paid to the sociocultural context in which idioms are consumed, even though idioms are social semiotic. Idioms are rooted in a particular culture and carry rich cultural elements (Chunke 2011). As such, idiom acquisition research should take into account the cultural frames of reference guiding the use of idiomatic expressions to fully account for how children acquire idiomatic

\section{http://repository.uwc.ac.za}


expressions. In this light, the current study took into consideration the sociocultural context in which Cicewa idioms are consumed as it investigated how native Cicewa- speaking children acquire the interpretation of Cicewa idioms. The study set out to answer these questions: To what extent does linguistic context facilitate the learning of idiomatic meaning? At what age do children start to use the information provided by the linguistic context to learn the idiomatic meaning? At what age do children become aware of idiomatic expressions as a category?

To fully answer the posed questions, the study adopted a Systemic Functional Linguistics (SFL) approach which treats language as a social semiotic system, thereby making idioms social semiotic in the meaning-making process. SFL helped us uncover the sociocultural contexts within which Cicewa idioms are consumed. It is hoped that this will help to resolve the existing contradictions regarding idiom acquisition.

\section{Systemic Functional Linguistics}

SFL is a descriptive and interpretative framework that views language as a resource for meaning- making in social and cultural contexts (Eggins 2004). It views language as a resource that speakers draw upon to accomplish their purposes by expressing meaning in context. 'Particular aspects of a given context define the meanings likely to be expressed and the language likely to be used to express those meanings' (Wattles and Radić-Bojanić 2007: 47). This is achieved through the 'system' and 'system network'. A system is 'a set of features which stand in contrast with each other in a specified environment - of which one will be chosen whenever the environmental conditions obtain' (Halliday 2009a: 66). Choice is the basic organising concept of the system as each system in a system network represents a point at which a choice has to be made (Eggins 2004); hence, a system is a point of choice (Matthiessen and Halliday 1997). A system allows for the encoding of paradigmatic relations in a language, thereby realising language as potential and language use as choice (Teich 1999).

SFL views language as stratified. It recognises three levels: lexico-grammar, semantics and context. The first two strata (lexico-grammar and semantics) are the 'content plane of language' and the third stratum (context) is called the 'expression plane of language'. SFL recognises threes modes of meaning (three metafunctions) in the 'content plane of language'. These modes of meaning are ideational, interpersonal and textual reflected in a huge system network of meaning potential (Haratyan 2011: 260). The ideational metafunction is concerned with human experience of the real world. It is the means for construing our experience of reality (both internal and external experiences) or 'going-on' of the world, that is, 'what kind of activities are undertaken, how participants in these activities are described, how they are classified and what they are composed of' (Martin and Rose 2003: 66). The interpersonal metafunction is concerned with enacting social roles, statuses and relationships between participants. Through the interpersonal metafunction 'users of language establish, negotiate and assume their position in social relationships' (Gallardo 2006: 738). Speakers make meanings about interpersonal dimensions such as 'the power or solidarity of their relationship; the extent of their intimacy; their level of familiarity with each other and their attitudes and judgements' (Eggins 2004: 184). All these three metafunctions 
are of equal status and none is more important than the other (Teich 1999). The textual metafunction is the way clauses are organised to form a unified text that makes meaning. Unlike the other two metafunctions (ideational and interpersonal), textual metafunction is intrinsic to language and it is at the helm of the creation of text. It is the level of organisation of the clause which enables the clause to be packaged in ways which make it effective given its purpose and its context' (Eggins 2004: 298). The textual strand of meaning is about cohesion and coherence, that is, the hanging together and making sense of a text.

However, critical to this paper is the SFL understanding of a 'text' as 'an instance of language in use' (Fawcett, 2008: 6). Thus, idioms as texts need to be understood within the social context in which they are produced and consumed. To Eggins (2004: 7) 'context is in a text: text carries with it, as a part of it, aspects of context in which it was produced and, presumably, within which it would be considered appropriate'. The social context, the total environment in which a text is created, bridges between a text and the situation in which texts actually occur (Halliday and Hasan 1989). Context, in SFL, is divided into context of situation (register), context of culture (genre) and ideology, with context of situation (register) and context of culture (genre) being the most discussed (Eggins 2004). In conceptualisation, the context of situation is above the context of culture, comprising social processes facilitated by language. Following Halliday (1978: 16), in terms of idiom production and consumption, the context of culture and the context of situation are not necessarily 'two things, but rather the same thing seen from two different depths of observation'. Context of culture refers to staged structured way (Eggins 2004) in which people use language to achieve culturally appropriate goals. It is the way in which people organise texts through language choices with an aim to achieve a social purpose. According to Martin (2009: 159), it is 'the system of staged goal-oriented social processes through which social subjects in a given culture live their lives'.

The context of culture (genre) is related to the context of situation (register) by instantiation. The relationship between the context of culture (genre) and the context of situation (register) is that context of situation is an instance of context of culture, potential (system) (Halliday 2009a). The context of situation is the immediate environment experienced, a pattern of linguistic choices and the context of culture is a pattern of register choices, a pattern of a pattern of texture (Martin 2009).

Thus, in exploring children's acquisition of idioms, we are interested in the age at which they are able to correctly instantiate, that is, to interpret and relate particular idioms to the social processes determining the immediate linguistic context (context of situation) and the wider context of culture in which they are expressed, comprising the 'field': the main social event; 'tenor': the identities, social roles and relationships of speakers and 'mode': the way text is used in organising the social activity/event. This entails exploring their knowledge of the overall conceivable situation types; and, in discursive terms, their knowledge of the potential range of linguistic resources that can be used to rework and reproduce a particular idiom in 
each particular situation. In SFL terms, we are also interested in uncovering children's knowledge of grammatical metaphor as instantiated in particular idiom usage.

Grammatical metaphor refers to the interstratal relationship, based on realisation, between semantics and lexico-grammar within the grammatical zone of lexico-grammar (Matthiessen, Teruya and Lam 2010). It is the inherent creative potential in the grammar that enables language users to de-couple the lexico-grammatical/semantic interface and to re-couple it with a different ordering (Halliday 2009b). Grammatical metaphor is the pattern of playing with the system, of using non-typical structures to express our meaning in ways that can be highly sensitive to contextual constraints, (Eggins 2004: 119). In grammatical metaphor, a meaning that was construed by one wording comes to be construed by another. Thus, grammatical metaphor involves the junction of category meanings and not of word meanings (Halliday 2009b).

Ontogenetically, metaphorical grammar develops late in children after the everyday grammar is already deeply installed. The metaphorical grammar and everyday grammar co-exist and interpenetrate and the individual moves freely between more and less elaborated modes of discourse. Experience is "modelled from both standpoints in order to get a rounded picture of "reality", one which will enable us to go on interacting in increasingly complex ways with our environment' (Halliday 2009b: 122).

Understanding how children learn to mean (Halliday 2009b) is central in SFL as the learning process provides evidence for key dimensions of the theory such as 'the stratificational and metafunctional organisation of language and the relation of text to both context and system' (Painter 2009: 87). SFL views language learning as a gradual process in which children build up the linguistic 'meaning potential' as they interact with others. Children's linguistic 'meaning potential' keeps changing as they interact with adults who have a different 'meaning potential'. In the interaction process, both children and adults negotiate an actual text which is meaningful and relevant to both of them. Through this process, 'the contingencies of the spontaneous interaction may lead to a new understanding or may lead the child to produce an utterance that is in some way 'beyond' what has gone before' (Painter 2000: 66). This kind of a text may disturb the current linguistic system, and if there is more evidence the child's linguistic system may adjust to accommodate new meaning choices. The child's linguistic system keeps adjusting as the child participates in meaning-making activities until it resembles the adult's system.

In this paper we utilise aspects of SFL such as social context, text, lexico-grammar, transitivity structure and grammatical metaphor. Cicewa idioms being texts which need to be interpreted in the context in which they are used, it is important to analyse the transitivity of Cicewa idioms and the social context in which Cicewa idioms are used, to fully understand and explain how Cicewa- speaking children acquire the meanings of Cicewa idiomatic expressions. In addition, an analysis of grammatical metaphor can reveal how the everyday grammar of experience is deconstrued and reconstrued metaphorically in 
Cicewa idioms. This kind of analysis can lead to an understanding of how children learn to interpret Cicewa idioms.

\section{Experiment 1}

The aim of this experiment was to test children's ability to understand idiomatic expressions when embedded in stories that are biased towards an idiomatic interpretation. It also aimed at identifying the age at which children start understanding idiomatic expressions. In this experiment, children were exposed to 20 familiar idioms embedded in different contexts that were biased towards an idiomatic interpretation. Children's ability to understand the idiomatic expressions was tested using a multiple- choice task that followed a short story ending with an idiom.

\section{Methods \\ Participants}

Twenty children who are native speakers of Cicewa participated in this experiment. The children were drawn from Mpalume Village, one of the areas that mostly use Cicewa, in Chinamawali Township, Zomba, Malawi. These children go to a primary school that teaches Cicewa as a mandatory subject and uses Cicewa as a medium of instruction in the lower classes; hence, they had many chances of encountering familiar Cicewa idiomatic expressions. Abrahamsen and Smith (2000: 228) state that 'children encounter idioms in both written and oral language as they progress through the school years'. These children come from families that use Cicewa all the time, so they had the opportunity of encountering idiomatic expressions very often. These children were in the following age groups: four years (range 4.1-4.11; mean 4.3), six years (range 6.0-6.11; mean 6.6), nine years (range 9.0-9.8; mean 9.3), twelve years (range 12.2-12.9; mean 12.5) and fourteen years (range 14.0-14.2; mean 14.1). For each age group, four children were selected. The four-year-olds were selected because they are not very much exposed to idioms because idiom comprehension starts when children are in school, mainly when they are seven years old and above (Levorato and Cacciari 1992; 1995). However, there is some observation that children around the age of four are able to handle non-literal expressions like idioms (Schnell 2007). So, the four-year-olds were selected to find out whether children as young as four are able to interpret idiomatic expressions figuratively. On the other hand, the fourteen-year-olds were selected because they have been exposed to and said to understand a good number of idioms (Levorato and Cacciari 1999).

All the children who participated in this experiment were normally/typically developing Cicewa native speaking children. The interview with parents revealed that all the children met the following exclusion criteria: diagnosis of a language disorder; severe learning difficulties or requirement for special educational services; schooling in a language other than Cicewa or not studying Cicewa at school; chronic disorder (e.g. diabetes); history of premature birth or low birth weight (e.g. birth weight $<2500 \mathrm{~g} / 5 \mathrm{lbs}$, and/or $<37$ weeks gestation) and history of hospitalisation or medical attention for a closed head injury (HuberOkrainee, Blaser and Dennis 2005). 


\section{Materials and procedure}

A total of 110 idioms were picked from Cicewa textbooks used in primary schools in Malawi. Firstly, these idioms were evaluated regarding their familiarity by 20 adult Cicewa native speakers, above the age of 25 years, as there are no frequency references available for idioms in Cicewa. The speakers were asked to say how frequently they had heard, seen or used each idiomatic expression without considering whether or not they knew what it meant, using a 4-point scale ranging from never (1) to very often (4). The idioms that they had never heard, seen or used were to be rated 1; idioms that they had heard, seen or used very often were to be rated 4 . From the idioms that were rated familiar, the top 40 were picked because research has shown that the most familiar idioms are the most meaningful (Schweigert and Cronk 1992/93; Titone and Connine 1994; Janyan and Andonova 2000; Kamanga 2007; 2012). For each idiom, a short story that was biased towards an idiomatic meaning was developed according to the schema proposed by story grammar - a setting followed by an episode. Each story had one idiom only which was at the end. The stories had an average number of 28 words. Each story was followed by a question: 'What does it mean that he/ she did (or was) ... idiom?' (e.g. What does it mean that he broke the ice?'). Then three options were provided: (a) an idiomatic interpretation of the string ('idiomatic' answer); (b) a paraphrase of the literal meaning ('literal' answer); (c) a response referring to an aspect of the context presented by the story but neither literal nor idiomatic ('filler' answer). This kind of a task has been used in various studies on idiom acquisition and it has proved to be a good test (Levorato, Roch and Nesi 2007). The developed stories were then presented to 10 primary school teachers for them to provide answers for validity. All the options were removed from the stories and the teachers were supposed to provide answers from their heads. Three teachers had problems interpreting two of the idioms and the stories containing the idioms that caused problems were removed from the list. Then stories with the top 20 most familiar idioms were picked from the remaining stories and used in this experiment. The idioms were reduced to 20 to avoid fatigue effects.

The experimenter engaged with each child individually, reading each of the 20 stories one at a time. If the child was nine years old or above, s/he was allowed to follow a printed version. At the end of each story, the researcher then read the question and the three answers to the child and then invited him/her to choose the answer s/he believed to be the most appropriate. The choice of the idiomatic answer showed that the child recognises the figurative meaning as appropriate in the context; the choice of the filler showed that the global meaning of the story is not grasped although the literal meaning is recognised as inappropriate; and the literal choice shows that 'a shallow processing of the text is performed and that the linguistic information undergoes a piece by piece analysis' (Levorato, Roch and Nesi 2007: 481). The experimenter marked the answers chosen by each child on the response sheet.

\section{Data coding and analysis}

The responses given by the children were coded for statistical analysis. An idiomatic response was assigned code 1, a literal response code 2 and a filler response code 3 . The data were analysed using the Statistical Package for Social Sciences (SPSS Version 22).

\section{http://repository.uwc.ac.za}


Descriptive statistics (frequencies) and inferential statistics (cross tabulations, correlation tests and analysis of variance (ANOVA)) with post-hoc test were conducted. Apart from analysing the data, the stories within which the idioms were embedded were analysed using Systemic Functional Linguistics to identify the sociocultural contexts within which the idioms were produced and meant to be interpreted. The lexico-grammatical analysis involved schematic structure, logical relations (clause complex), mood, transitivity (process type), theme, conjunctive relations, lexical relations and reference.

\section{Results}

Table 1 shows the frequency of each type of response when idioms were embedded in stories biased towards an idiomatic interpretation. The frequency of responses indicates that 'idiomatic' responses 236 (59\%) were predominant when idioms were embedded in stories and that 'literal' responses 59 (14.8\%) were less preferred. The 'filler' responses 105 (26.3\%) were preferred more than 'literal' responses.

In order to determine which age groups produced more of these response types, a crosstabulation of 'response type' against 'age' was done. Figure 1 shows which age group chose what type of response. Figure 1 reveals that four-year-olds chose 'filler' responses more (52) than any other age group.

It also shows that four-year-olds chose more 'filler' responses than 'literal' responses (16), and that they chose the least 'idiomatic' responses (12) than any other age group. The four-year-olds idiomatically interpreted idioms like mwana alilenji (lack nothing) and tsala madzi amodzi (be about to die or to be caught).

Six-year-olds chose 31 'filler' responses, 16 'literal' responses and 33 'idiomatic' responses. They idiomatically interpreted idioms like ona nsana wanjila (return/go back), mwana alilenji (lack nothing), uma mutu (be dull), ika kampeni kumphasa (plot against someone), onela pakhosi (be seriously ill), tsala madzi amodzi (be about to die or to be caught), galu wakuda (famine), tsamila dzanja (die) and kupha phala (to drink beer a lot).

Fourteen-year-olds chose idiomatic responses most often (78), followed by twelve-year-olds (65) and then nine-year-olds (48). However, some fourteen-year-olds still failed to correctly interpret some idioms like khala maso (be alert) in the story context. 


\begin{tabular}{lcccc}
\hline & Frequency & Per cent & Valid per cent & Cumulative per cent \\
\hline Idiomatic & 236 & 59.0 & 59.0 & 59.0 \\
Literal & 59 & 14.8 & 14.8 & 73.8 \\
Filler & 105 & 26.3 & 26.3 & 100.0 \\
Total & 400 & 100.0 & 100.0 & \\
\hline
\end{tabular}

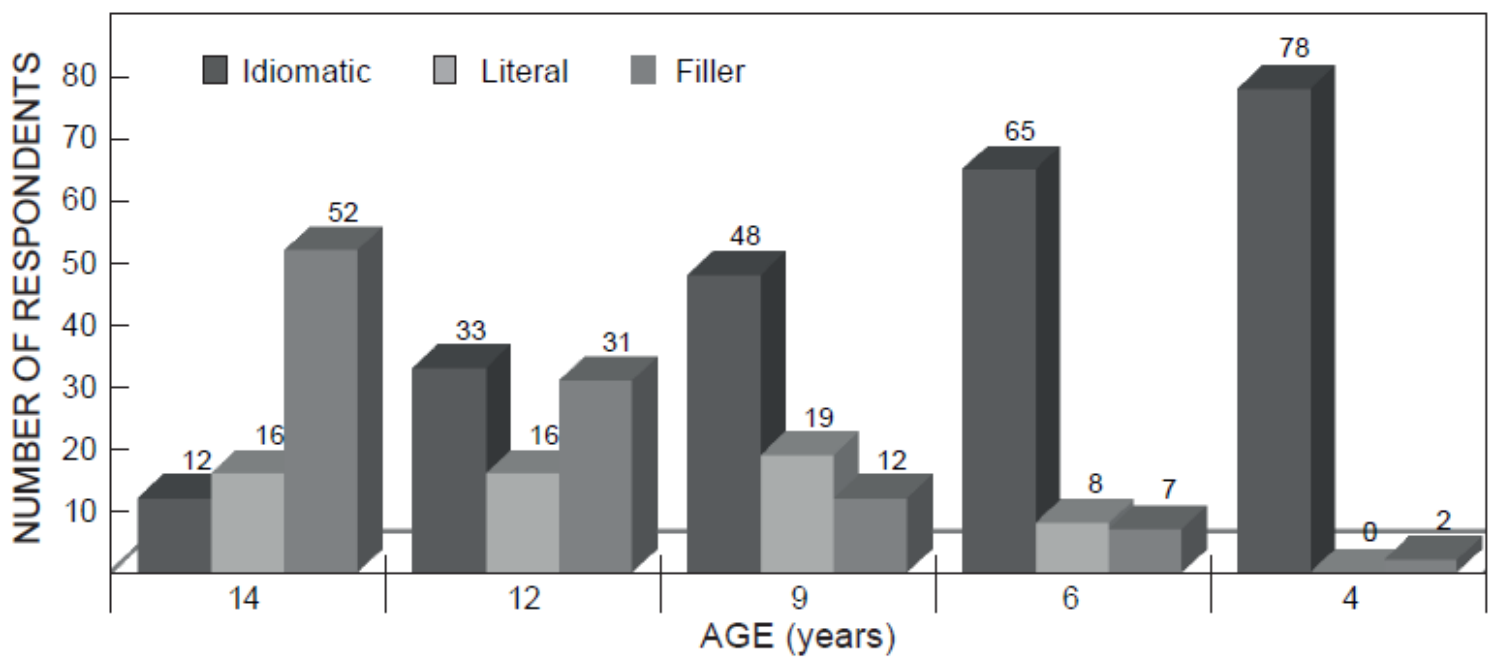

Figure 1: Response type against age in story context

Figure 1 also shows that nine-year-olds selected more 'literal' responses (19) than any other age group. For example, three nine-year-olds interpreted galu wakuda ('black dog' = famine) literally in the story context.

The one-way between-groups analysis of variance (ANOVA Test) with post-hoc Tukey tests with age as an independent variable showed that the responses of the five age groups were significantly different in the story context $(F(4,395)=55.059, p<0.0001)$. The post-hoc Tukey tests indicated that in the story context there were significant differences in the responses between four-year-olds and six-year-olds, nine-year-olds, twelve-year-olds, and fourteen-year-olds $(p<0.001)$; there were significant differences in the responses between six-year-olds and nine-year-olds, twelve-year-olds and fourteen-year-olds $(p<0.001)$; there was no significant difference in the responses between nine-year-olds and twelve-year-olds $(p>0.05)$ but there were significant differences in the responses between nine-year-olds and fourteen-year-olds $(p<0.001)$; there was no significant difference in the responses between twelve-year-olds and fourteen-year-olds $(p>0.05)$.

The relationship between age and response type was investigated using Pearson productmoment correlation coefficient. The correlation was significant at the 0.01 level (2-tailed). The Pearson correlation showed a strong negative correlation between age and response type, $r=-0.587, n=400, p<0.0005$. The non-idiomatic responses decreased with age. 


\section{Experiment 2}

This experiment aimed at testing whether children are able to interpret idiomatic expressions using the contextual cues provided by the sentences leading to the identification of the contextually appropriate interpretation. It also tested the age at which children start searching for the contextual cues to arrive at the appropriate meaning. In this experiment, children were exposed to 20 sentences containing idiomatic expressions that the children were exposed to in Experiment 1.

\section{Methods}

\section{Participants and materials}

The same 20 children who took part in Experiment 1 participated in this experiment, one month after the completion of Experiment 1. A list of sentences containing idiomatic expressions was used to collect the data. The sentences contained the idiomatic expressions that the children were exposed to in Experiment 1. Unlike in Experiment 1, no answers were provided for the sentences, but the same question was raised: 'What does it mean that he/she did (or was) ... idiom?' (e.g. What does it mean that he broke the ice?'). Children had to provide the meanings from their heads using the context provided by the sentence.

\section{Procedure}

The experimenter engaged with each child individually, reading each of the sentences one at a time. If the child was nine years old or above, s/he was allowed to follow a printed version. After reading the sentence, the experimenter asked the child to answer the question: 'What does it mean that he/ she did (or was) ... idiom?' (e.g. What does it mean that he broke the ice?'). The child had to answer this question before the next sentence was read. No answers were provided by the experimenter for the child to choose from. The children had to find answers on their own. Each child was tested individually, and the order of the idioms was the same. The experimenter recorded the answers given by each child on the response sheet.

\section{Data coding and analysis}

The data were analysed in two phases. In the first phase the data were qualitatively analysed and in the second phase they were quantitatively analysed. In the qualitative analysis, the responses were compared several times to identify patterns, differences and similarities. It involved identification of types of responses given by the children in the experiment. The identified response types were named accordingly. After identifying the response types, they were coded for statistical analysis. The lexico-grammatical analysis of the responses was also done using Systemic Functional Linguistics, to identify the sociocultural context within which children interpreted the idioms. In the second phase of analysis, the data were statistically analysed using Statistical Package for Social Sciences (SPSS Version 22). Descriptive statistics (frequencies) and inferential statistics (cross tabulations, correlation tests and analysis of variance (ANOVA)) with post-hoc test were conducted.

\section{Results}

Table 2 summarises the frequency of the response types in the sentence context. Idiomatic responses 139 (34.8\%) and 'same idiom' 118 (29.5\%) (a response in which 
children gave back the idiom as an answer) were predominant. Irrelevant responses 67 (16.8\%) (a response that was not related, in any way, to the sentence or the idiom in question) were also common and the literal response 18 (4.5\%) were less preferred. The other response types given by children are 'associative' 27 (6.8\%) (a response related to part of the sentence or part of the idiom), 'related to idiomatic meaning' 25 (6.3\%) (a response that was closely related to the idiomatic meaning of the idiom) and 'no response' 6 (1.5\%) (where children did not give any answer).

To determine which age groups produced more of these response types, a cross-tabulation of 'response type' against 'age' was done. Figure 2 shows which age group produced what type of response.

Figure 2 shows that four-year-olds and six-year-olds produced zero (o) idiomatic meaning and that six-year-olds gave more 'associative' meanings than any other age group. To illustrate, the idiomatic expression tsala madzi amodzi in Nkhuku yanga yatsala madzi amodzi ili ndi chitopa ('My chicken has remained one water it has Newcastle' = My chicken is about to die, it has Newcastle) was interpreted as ikudwala chitopa (it is suffering from Newcastle) instead of 'it is about to die'. 


\begin{tabular}{llcccc}
\hline & Frequency & Per & Valid & Cumulative \\
& & & cent & Per cent & \begin{tabular}{c} 
per cent \\
\hline Valid
\end{tabular} Idiomatic \\
& Literal & 139 & 34.8 & 34.8 & 34.8 \\
& Associative & 18 & 4.5 & 4.5 & 39.3 \\
& Related to idiomatic meaning & 27 & 6.8 & 6.8 & 46.0 \\
& Same idiom & 25 & 6.3 & 6.3 & 52.3 \\
& Irrelevant & 118 & 29.5 & 29.5 & 81.8 \\
& No response & 67 & 16.8 & 16.8 & 98.5 \\
& Total & 6 & 1.5 & 1.5 & 100.0 \\
\hline
\end{tabular}

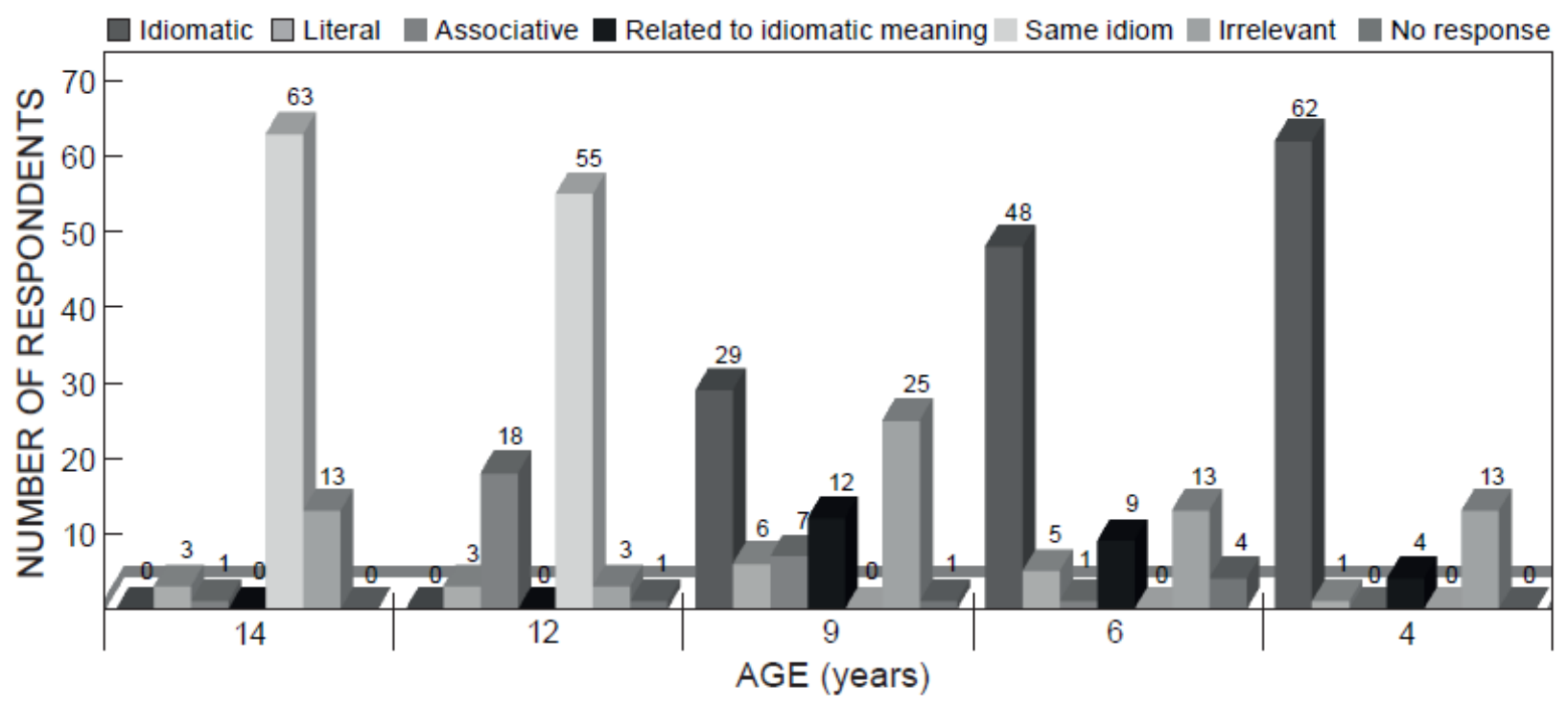

Figure 2: Response type against age in sentence context

Nine-year-olds produced least of the idiomatic interpretations (29) but produced more of the other responses: 'irrelevant' meanings (25), meanings 'related to idiomatic meaning' (12), associative meanings (7) and literal meanings (6). To illustrate, they idiomatically interpreted ona nsana wanjila ('see the back of the road' = go back/return) when embedded in Tabwela lija ndi kale tiwone nsana wanjila tsopano (It's long time when we arrived, we should go back now) as abwelele kunyumba (they should go back home); tilondole kunyumba (we should go home) and tibwelele kunyumba (we should go home) but failed to idiomatically interpret gona pamphepo ('sleep where it's cold' = not married) when embedded in Gumede akugona pamphepo chifukwa akazi amangomukana ('Gumede is sleeping where it's cold because women refuse him' = Gumene has not married because women refuse him). The idiom was interpreted as akazi amangomukana (women refuse him), akugona pozizila (he is sleeping at a cold place), akugona popanda nyumba (he is sleeping where there is no house). 
Fourteen-year-olds gave more idiomatic meanings (62) than any other age group followed by twelve-year-olds (48). For instance, fourteen-year-olds idiomatically interpreted malo oduka mphepo ('a place where the wind is cut' = a secluded place), an idiom which could not be idiomatically interpreted by the other age groups. However, the fourteen-year-olds also produced a good number of 'irrelevant' meanings (13). For instance, all fourteen-yearolds failed to figuratively interpret the idiom dyela masuku pamutu ('eat masuku (wild loquat/Uapaca kirkiana) from one's head' = exploit someone) when this idiom was presented in this sentence Chikondi amakonda kudyela masuku pamutu anzake ('Chikondi likes to eat masuku from the heads of his/her friends' = Chikondi likes to exploit her/his friends).

The one-way between-groups Analysis of Variance (ANOVA Test) with post-hoc Tukey tests with age as independent variable showed that the responses of the five age groups were significantly different in the sentence context $(F(4,395)=45.280, p<0.0001)$. The post-hoc Tukey tests indicated that in the sentence context there were no significant differences in the responses between four-year- olds and six-year-olds $(p>0.05)$; there were significant differences in the responses between four-year-olds and nine-year-olds, twelve-year-olds, and fourteen-year-olds $(p<0.001)$; there were significant differences in the responses between six-year-olds and nine-year-olds, twelve-year-olds and fourteen-year-olds ( $p<$ o.001); there were significant differences in the responses between nine-year-olds and twelve-year-olds $(p=0.027)$; there were significant differences in the responses between nine-year-olds and fourteen-year-olds $(p<0.001)$; there was no significant difference in the responses between twelve-year-olds and fourteen-year-olds $(p>0.05)$.

The relationship between age and response type was investigated using Pearson productmoment correlation coefficient. The correlation was significant at the 0.01 level (2-tailed). The Pearson correlation showed a strong negative correlation between age and response type, $r=-0.559, n=400, p<0.0005$. The non-idiomatic responses decreased with age.

\section{Experiment 3}

This experiment tested children's ability to understand idiomatic expressions out of context. It aimed at identifying the age at which a child is able to interpret idiomatic expressions out of context. In this experiment, children were exposed to a list of twenty idiomatic expressions that the children were exposed to in Experiment 1 and Experiment 2.

\section{Methods}

\section{Participants and materials}

The same 20 children who took part in Experiment 1 and Experiment 2 participated in this experiment, one month after the completion of Experiment 2. A list of 20 idiomatic expressions that the children were exposed to in Experiments 1 and 2 was used to collect the data, but in this list no context was provided and also no answers were provided. 


\section{Procedure}

The experimenter read the idioms to each child individually. Those aged six and below listened only while those aged nine and above followed on a printed version. After reading each idiomatic expression, the experimenter asked the child to say what the idiomatic expression meant. The child had to answer this question before the next idiomatic expression was read. No answers were provided by the experimenter for the child to choose from. The child had to find answers on her/ his own. Each child was tested individually, and the idioms were presented in the same order. The experimenter recorded the answers given by each child on the response sheet.

\section{Data coding and analysis}

To analyse the data, the data analysis and coding procedure followed in Experiment 2 was also followed in this experiment.

\section{Results}

Table 3 presents the frequency of response type in out of context. 'Same idiom' 136 (34.0\%) (a response in which children gave back the idiom as an answer) and 'idiomatic' responses 135 (33.8\%) were predominant. 'Irrelevant' responses 52 (13.0\%) (a response that was not related, in any way, to the idiom in question) were also common. Literal responses 39 (9.8\%), responses related to idiomatic meaning 26 (6.5\%) (a response that was closely related to the idiomatic meaning of the idiom), same idiom with modification 8 (2.0\%) (a response in which children gave back the idiom as an answer but the idiom was modified by adding an adjective or adverb), associative response 2 (0.5\%) (a response related to part of the idiom) and no response $2(0.5 \%)$ (where children did not give any answer) were also produced. 
Table 3: Frequency of response type in out of context

\begin{tabular}{|c|c|c|c|c|c|}
\hline & & Frequency & $\begin{array}{l}\text { Per } \\
\text { cent }\end{array}$ & $\begin{array}{c}\text { Valid } \\
\text { per cent }\end{array}$ & $\begin{array}{c}\text { Cumulative } \\
\text { per cent }\end{array}$ \\
\hline & Idiomatic & 135 & 33.8 & 33.8 & 33.8 \\
\hline & Literal & 39 & 9.8 & 9.8 & 43.5 \\
\hline & Associative & 2 & 0.5 & 0.5 & 44.0 \\
\hline & Related to idiomatic meaning & 26 & 6.5 & 6.5 & 50.5 \\
\hline \multirow[t]{5}{*}{ Valid } & Same idiom & 136 & 34.0 & 34.0 & 84.5 \\
\hline & Same idiom with modification & 8 & 2.0 & 2.0 & 86.5 \\
\hline & Irrelevant & 52 & 13.0 & 13.0 & 99.5 \\
\hline & No response & 2 & 0.5 & 0.5 & 100.0 \\
\hline & Total & 400 & 100.0 & 100.0 & \\
\hline
\end{tabular}

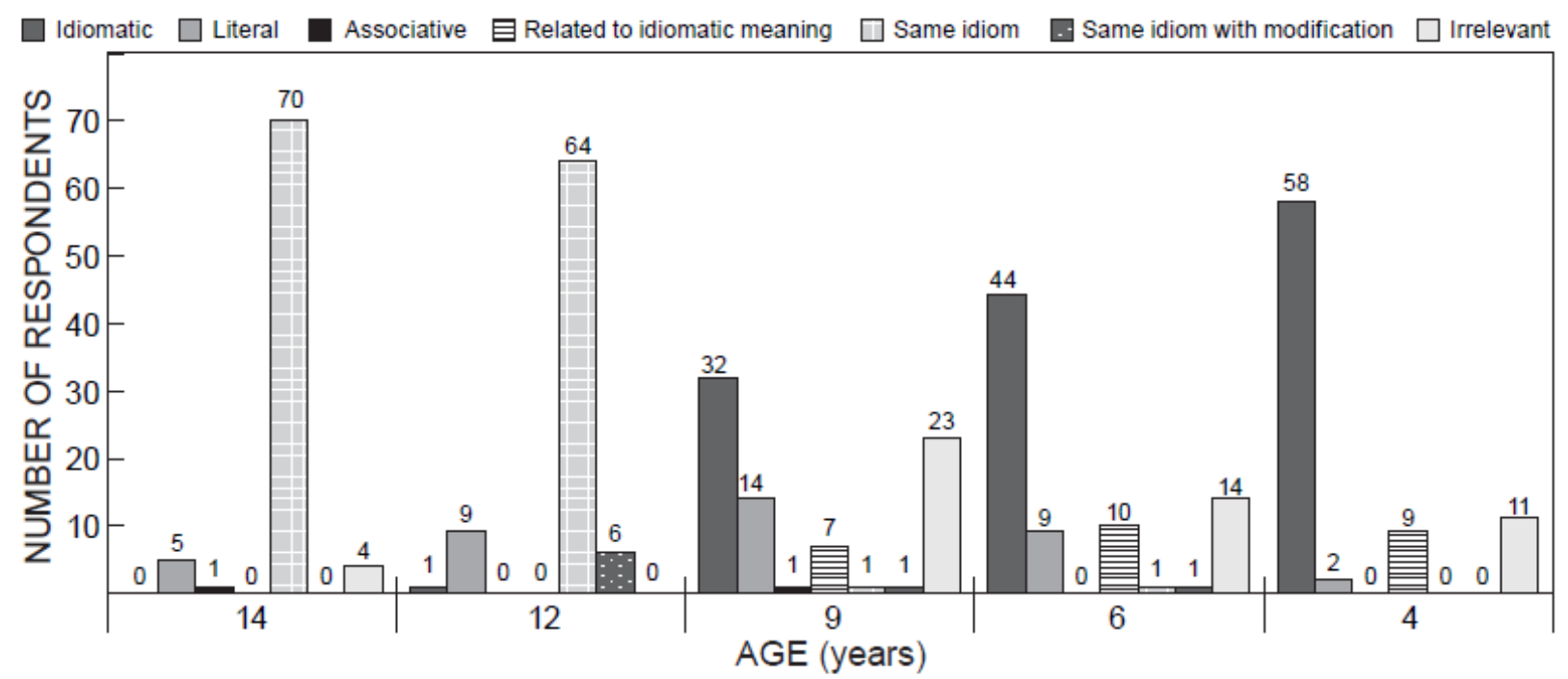

Figure 3: Response type against age in out of context

A cross-tabulation of 'response type' against 'age' was done to determine which age groups produced more of these response types. Figure 3 shows which age group produced what type of response.

Figure 3 shows that four-year-olds and six-year-olds gave back the 'same idiom' (a response in which children gave back the idiom as an answer), 70 and 64 respectively.

Nine-year-olds produced the least number of idiomatic interpretations (32), but they produced more 'irrelevant' meanings (23) and literal meanings (14) than any other age group.

Twelve-year-olds produced more idiomatic interpretations (44) than nine-year-olds, but they produced fewer idiomatic interpretations than fourteen-year-olds (58). Twelveyear-olds also produced more interpretations that were 'related to idiomatic meaning' (10) 
than any other age group. 'Irrelevant' meanings (11) and meanings 'related to idiomatic meaning' (9) were also present among fourteen-year-olds.

The one-way between-groups analysis of variance (ANOVA Test) with post-hoc Tukey tests with age as an independent variable showed that the responses of the five age groups were significantly different in the out of context interpretation $(F(4,395)=29.223, p<0.0001)$. The post-hoc Tukey tests indicated that in the out of context interpretation there were no significant differences in the responses between four-year-olds and six-year-olds $(p>$ 0.05); there were significant differences in the responses between four-year-olds and nineyear-olds, twelve-year-olds, and fourteen-year- olds $(p<0.001)$; there were significant differences in the responses between six-year-olds and nine-year-olds, twelve-year-olds and fourteen-year-olds ( $p<0.001)$; there were no significant differences in the responses between nine-year-olds and twelve-year-olds $(p>0.05)$; there were significant differences in the responses between nine-year-olds and fourteen-year-olds $(p=0.001)$; there was no significant difference in the responses between twelve-year-olds and fourteenyear- olds $(p>0.05)$.

The relationship between age and response type was investigated using Pearson productmoment correlation coefficient. The correlation was significant at the 0.01 level (2-tailed). The Pearson correlation showed a negative correlation between age and response type, $r=$ $-0.473, n=400, p<0.0005$. The non-idiomatic responses decreased with age.

\section{Summary of results from Experiments 1, 2 and 3}

To arrive at a well-informed conclusion, the results from the three experiments (Experiments 1, 2 and 3) have been summarised in Figure 4.

Figure 4 shows that the linguistically supportive context in Experiment 1 triggered more idiomatic responses than sentence context (Experiment 2) and out of context (Experiment 3). 


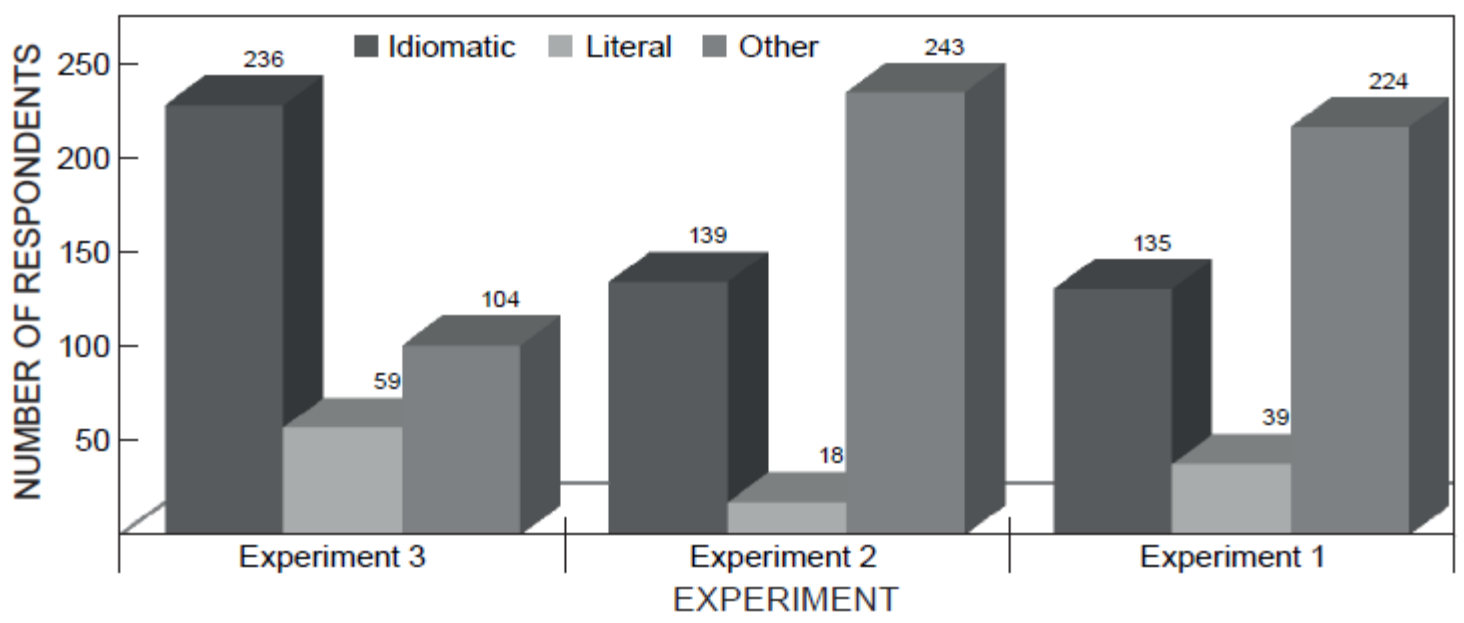

Figure 4: Summary of response types in Experiments 1, 2 and 3

\section{Discussion}

It seems from the study, as will be further discussed below, that there are restrictions to younger children's ability to fully appreciate that the meanings of idioms, depend on the context of situation (the speech activities/events and environment in which they are produced), as well as the context of culture (the overall context that gives meaning to idiom production/consumption as a culturally recognised activity). As was evident, although the children would sometimes recognise that idioms are instantiated in particular context of situation whose meaning is embedded in the context of culture, they still lacked the knowledge to interpret them correctly. Our argument is that the ability to interpret idioms as linguistic or textual choices relate to the ability to interpret what in SFL are called register variables of field, tenor and mode (cf. Eggins 2004). In essence, the younger and hence less experienced children often failed to fully appreciate the field of discourse, that is, 'what the language is being used to talk about' (Eggins 2004: 52) compared to the older children. Field, includes knowledge about the range of topics in which the idiom can be used. Appreciation of the tenor of discourse entails some knowledge of social roles and relationships assumed in particular idioms; and appreciation of mode of discourse presupposes knowledge of how language (whether spoken, written, nonverbal or multimodal) constructs what is going on in the context (cf. Eggins 2004; Martin 1992). In SFL, field, tenor and mode as aspects of context are embedded in the text through 'being realised in the semantic and grammatical structures of the text' (Graber 2001: 12). The younger Cicewa speakers showed limited or no knowledge of idioms as special kinds of language used to achieve particular social goals. They also showed little or no experience in finding the connection between an idiom as a text and its context. As a result, they were not always able to retrieve the linguistically relevant aspects of the co(n)texts through a scrutiny of the lexico- grammatical structure of the idiom. As Halliday and Hasan (1989) have argued, in SFL the lexico- grammar constituting the text predicts the situational contexts in which the language is used and vice versa. On the other hand, the more culturally knowledgeable and experienced older children were able to use this 
predictability to successfully link different idioms as texts to their associated contexts and meanings.

Thus, in terms of idiom production and consumption, the older children can be said to be able to perceive the context of culture and context of situation even without added contextual clues which gave them an (added) advantage in constructing and extracting required meanings. The younger children seemed to perceive meaning more correctly when the link between the contexts of situation and context of culture were particularly marked with additional contextual clues.

In general, our results support the claim by Huber-Okrainee, Blaser and Dennis (2005) that linguistically supportive context helps young children to infer the figurative meaning of an idiom. In this study, children produced more idiomatic interpretations when the idioms were presented in stories in Experiment 1 than when they were presented in sentences in Experiment 2 and out of context in Experiment 3. This is consistent with the findings by Cacciari and Levorato (1998), Levorato and Cacciari (1992; 1999), Laval and Bernicot (2002), Laval (2003), Levorato, Nesi and Cacciari (2004) and Hsieh and Hsu (2010) who found that children provided more idiomatic answers when idioms were embedded in supportive contexts than when context was not available. The linguistically supportive context triggered idiomatic responses even in the youngest children, the fouryear-olds who failed to provide any idiomatic response in Experiment 2 (where idioms were presented in sentences) and Experiment 3 (where idioms were presented out of context). This is consistent with the findings of Schnell (2007) who found that children around the age of four years are able to handle non-literal expressions like idioms. The sixyear-olds also produced idiomatic responses (33) in the story context but they produced no idiomatic responses in the sentence context and one idiomatic response in the out of context. The findings also suggest that the linguistic patterns in the stories helped not only the four-year-olds and six-year-olds, but also the nine-to-fourteen-year-olds to determine the dimensions of reality being talked about; hence the idiomatic responses. The predominance of the idiomatic responses in six-year-olds in the story context suggests that the awareness of the 'cultural frames of reference and meaning' (Lirola 2005: 19) has already started at this age, although the filler responses are still predominant.

In this study, literal responses were not popular among all age groups in all three experiments. Even the youngest children, four-year-olds and six-year-olds, avoided literal responses even when the idioms were presented out of context. For instance, in the story context in Experiment 1, four-year-olds chose more 'filler' responses (52) than 'literal' responses (16) and six-year-olds chose more 'filler' responses (31) than 'literal' responses (16). These findings are in conflict with the findings of other studies (Prinz 1983; Abkarian et al. 1992; Levorato 1993; Vulchanova, Vulchanov and Stankova 2011) who reported that young children aged six years and below tend to interpret idioms literally. However, the findings are consistent with the findings of Laval (2003), Leung (2011) and Hsieh and Hsu (2010) who reported that children aged six years are able to give responses that are context dependent. The predominance of 'filler' responses over 'literal' responses 
suggests that Cicewa-speaking children, as young as four years, were able to use the information provided by the linguistic context to interpret the idioms. They detected that the literal meaning was in conflict with the linguistic context within which the idiom was embedded, but they were not able to grasp the global meaning of the story (Levorato, Roch and Nesi 2007). Consequently, they chose a 'filler' response because it seemed plausible in the present linguistic context. This suggests that children as young as four years are able to use the information provided by the linguistic context to interpret idioms, but they fail to correctly interpret the idioms because they fail to go beyond the linguistic context. As a result, they cannot determine the dimensions of reality being talked about. The meaning of an idiom depends on the agreed upon linguistic convention shared by a specific language community that relates a given linguistic form to a non-literal meaning (Hsieh and Hsu 2010). In addition, Thyab (2016) observes that idioms are based on every language's history, heritage and culture. This suggests that linguistic context alone is not enough for one to interpret idioms.

Four-year-olds and six-year-olds were the only ones who gave back the same idiom in the sentence context and out of context. The predominance of 'same idiom' among four-yearolds and six-year- olds indicates that Cicewa-speaking children were able to recognise idioms as instances of use that need to be interpreted within the social contexts in which they are produced. As a result, they avoided interpreting the idioms literally. Instead, they gave the idiom back without interpreting it, possibly because they lacked knowledge of the social contexts within which the idioms are consumed. Eggins (2004: 7) states that a 'text carries with it, as a part of it, aspects of the context in which it was produced and, presumably, within which it would be considered appropriate'. Thus, it can be argued that four-year-olds are not able to deduce the sociocultural context within which the idioms are used from the linguistic patterns in the stories. Accordingly, they fail to correctly interpret the idioms even though they are aware that the literal meaning is not appropriate. Hence, it can be suggested that Cicewa-speaking children as young as four years are able to recognise idioms as instances of use that need to be interpreted within the social context in which they are produced, although they have not yet developed the awareness of the 'cultural frames of reference and meaning' (Lirola 2005: 19) guiding the use of Cicewa idiomatic expressions. Therefore, we argue that idioms are texts which need to be interpreted and acquired within the sociocultural context in which they are produced.

The six-year-olds also gave more 'associative' meanings in the sentence context than any other age group. This suggests that six-year-olds are able to use contextual cues in their efforts to interpret idioms, but the contextual cues provided by the linguistic context are insufficient to enable them to appropriately interpret the idioms. For instance, six-yearolds interpreted tsala madzi amodzi in Nkhuku yanga yatsala madzi amodzi ili ndi chitopa ('My chicken has remained one water it has Newcastle' = My chicken is about to die, it has Newcastle) as ikudwala chitopa (it is suffering from Newcastle) instead of idiomatically interpreting it as 'it is about to die'. For these children to arrive at this associative interpretation, they used the available contextual cues. The children associated chitopa (Newcastle) with nkhuku (chicken) hence the interpretation ikudwala chitopa (the

\section{http://repository.uwc.ac.za}


chicken is suffering from Newcastle). These children lacked knowledge of the social context guiding the use of the idiom tsala madzi amodzi. The idiom lacks literal meaning because the literal meaning (remain one water) contradicts the world knowledge as it is not possible to count water. However, Cicewa speakers believe that water is a source of life, and among the Cewas there is a saying that says madzi ndi moyo (water is life). This belief makes Cicewa speakers equate water with life, thereby interpreting tsala madzi amodzi as 'be about to die'. In this social context, the expression is understood as very little life is remaining. Kamanga (2007) explains that when Cicewa speakers hear the expression tsala madzi amodzi they visualise a bucket/basin containing very little water in it. If the water evaporates, no water will remain in the bucket/basin since there is already very little water. Hence, the meaning 'be about to die' does not contradict Cicewa speakers' world knowledge. Lack of knowledge of the social context in which the idiomatic expression tsala madzi amodzi is consumed led six-year-olds to look for the meaning that would be appropriate in the context, hence they opted for ikudwala chitopa. These children also failed to recognise the metaphorical nature of the idiom although they have knowledge of the lexico-grammar. They did not realise that 'the selection of metaphor is itself a meaningful choice' (Halliday 1985: 321) because the knowledge of metaphor has not yet developed at this age. This leads to the conclusion that children aged six years and below are able to recognise idioms as texts that need to be interpreted in a special way. However, they lack knowledge of metaphor and knowledge of the sociocultural context in which idioms are produced and need to be interpreted, although they are able to use contextual cues to infer the appropriate sense of the idiomatic expression in their effort to interpret the idiom.

The findings also show that nine-year-olds, twelve-year-olds and fourteen-year-olds were able to interpret idioms figuratively in all contexts (story context, sentence context and out of context), although nine-year-olds produced the least idiomatic responses. Nine-yearolds were able to interpret idioms figuratively in all three contexts because at this age a child has acquired some knowledge of cultural frames of reference in which the idioms are rooted and knowledge of metaphor (Halliday 2009b). Therefore, a child aged nine years is aware that the selection of metaphor is a meaningful choice even though the text may seem ungrammatical and lack a literal interpretation. So, the child is able to deduce the dimensions of reality being talked about and search for a meaning that would be appropriate in the context. To illustrate, three nine-year old children were able to interpret the idiom ona nsana wanjila ('see the back of the road' = go back/return) figuratively when it was embedded in the following sentence Tabwela lija ndi kale tiwone nsana wanjila tsopano (It's long time when we arrived, we should go back now). This suggests that these children have knowledge of both metaphor and the sociocultural context in which the idiom is used. This idiom is a metaphor because it contains what in SFL is called a verb of mental process 'ona' (see) with an object which has no front or back 'njila' (the road/path) as phenomenon. 'Njila' cannot be perceived as having a back as this contradicts our world knowledge. However, despite this internal contradiction, nine-year-olds were able to realise that the selection of a metaphor is meaningful. Thus, they searched for the meaning of the idiom although it has no literal interpretation. These children also had the sociocultural knowledge guiding the use of the idiom. Although a road/path cannot be perceived to have a back or a 
front, the world knowledge informs Cicewa speakers that when someone is going back/returning she/he (re) traces the route she/he used, and in the rural areas of Malawi there are mostly footpaths that have no tarmac. In this case, the person can actually see her/his footprints she/he made when coming. The part of the road that one actually sees, with the footprints, is perceived as its back. So, these nine-year-olds have this sociocultural knowledge and they appropriately interpreted the idiom as abwelele kunyumba (they should go back home); tilondole kunyumba (we should go home) and tibwelele kunyumba (we should go home).

Although nine-year-olds were able to interpret the idiom ona nsana wanjila appropriately, they failed to appropriately interpret the idiom gona pamphepo ('sleeping where it's cold' = not married). None of the nine-year-olds interpreted this idiom figuratively when it was presented in the sentence Gumede akugona pamphepo chifukwa akazi amangomukana ('Gumede is sleeping where it's cold because women refuse him' = Gumene has not married because women refuse him). One of the children interpreted it as akugona popanda nyumba (he is sleeping where there is no house) an interpretation which was irrelevant. However, this child used the information provided by the sentence, his world experience and reasoning to arrive at the interpretation he gave. The second child interpreted it as akazi amangomukana (women refuse him) an interpretation which was deduced from the provided linguistic context. The third child interpreted it literally as akugona pozizila (he is sleeping at a cold place). The last child interpreted it as akungomukana (they are refusing him) an interpretation based on linguistic context. All these interpretations indicate that these nine-year-olds lacked knowledge of the cultural frames of reference for the idiomatic use of the idiom gona pamphepo (sleep where it's cold). The Cewas believe that because a man and a wife sleep very close to each other, the heat radiated by the human body is double, thereby, keeping the place warm. Even if it might be cold around them, they do not feel the cold. Someone who is not married relies on his/her own body heat only. So, when it is cold, she/he feels the cold. The nine-year-olds lacked this sociocultural knowledge. As a result, they all failed to interpret the idiom figuratively. This suggests that idiomatic expressions as texts are acquired together with the sociocultural context in which they are produced and consumed, and the sociocultural context forms part of the idioms. It can also be suggested that although nine-year-olds have access to other cultural frames of reference, some references have not yet developed at this age.

Twelve-year-olds produced more idiomatic interpretations than nine-year-olds but they produced fewer idiomatic interpretations than fourteen-year-olds in all the three experiments. The increase in idiomatic interpretations provided by the twelve-year-olds indicates that at the age of twelve knowledge of sociocultural context is greater than at the age of nine but it is still lower than the knowledge a fourteen-year-old has. The knowledge of the cultural frames of reference is still developing at age twelve. As a result, the child can deduce dimensions of reality that are not correct and select meaning choices that are inappropriate. 
The fourteen-year-olds provided more idiomatic interpretations in all the three contexts (story context, sentence context and out of context) than all the other age groups. This supports the findings of Karuppali and Bhat (2013) who found that fourteen-year-olds are able to interpret most idioms idiomatically. It can be suggested that at the age fourteen, a child is aware of the sociocultural context in which the idioms are used. The prevalence of idiomatic interpretations among fourteen- year-olds indicates that at the age fourteen children are aware of the sociocultural context in which the idioms are consumed. It also indicates that the knowledge of metaphor has reached maturation. As a result, children are able to realise that the selection of metaphor is a meaningful choice and are able to deduce the dimensions of reality being talked about. Consequently, they search for a meaning that would be appropriate even though the text may seem ungrammatical and lack a literal interpretation. For instance, fourteen-year-olds were able to appropriately interpret malo oduka mphepo ('a place where the wind is cut' = a secluded place) which could not be interpreted by the other age groups. Fourteen-year-olds gave the idiomatic meaning 'secluded place' for the idiom malo oduka mphepo when it was embedded in this sentence Tikambilane nkhaniyi pa malo oduka mphepo ('We should discuss this issue at a place where the wind is cut' $=$ we should discuss this issue at a secluded place). This idiom malo oduka mphepo is a metaphor, therefore, ungrammatical nominal group because the modifier oduka mphepo (where the wind is cut) is ill-formed in that mphepo (wind) cannot be cut although we can feel it. Thus, it lacks literal meaning because it contradicts our world knowledge. Despite the contradiction, fourteen-year-olds were able to recognise the idiom malo oduka mphepo as a meaningful choice, and interpreted it figuratively because they have knowledge of both metaphor and the sociocultural information guiding the use of the idiom. Cicewa speakers have the knowledge that wind transmits sound and that sound cannot be transmitted if there is no wind. If people converse in a place where there is no wind (where the air is still) they are able to hear each other because the still air vibrates but other people who are outside this area will not hear the conversation (Kamanga 2007). In this sense this place is believed to be secluded; hence it is a safe place to discuss private and secret issues. The fourteen-yearolds had access to this information and they figuratively interpreted the idiom which all the other age groups failed to interpret idiomatically. It can be suggested that at the age of fourteen years the child's knowledge of idiomatic meanings starts resembling that of adults.

Although fourteen-year-olds were able to idiomatically interpret idiomatic expressions that children in the other age groups could not interpret, fourteen-year-olds still had problems in interpreting some idioms, as they also produced a good number of non-idiomatic responses. For instance, all fourteen- year-olds failed to figuratively interpret the idiom dyela masuku pamutu ('eat masuku (wild loquat/ Uapaca kirkiana) from one's head' = exploit someone) which also caused the other age groups problems. When this idiom was presented in this sentence Chikondi amakonda kudyela masuku pamutu anzake (Chikondi likes to eat masuku from the heads of his/her friends = Chikondi likes to exploit her/his friends) all fourteen-year-olds provided interpretations that were irrelevant, that were based on their experience and the available linguistic context. These children lacked knowledge of the cultural frames guiding the use of this idiom. The meaning of the idiom is drawn from a situation where young people go to gather masuku (wild loquat/Uapaca kirkiana) from the

\section{http://repository.uwc.ac.za}


bush, and when enough have been gathered, they are put in one basket to be shared equally at home. The youngest person carries the basket (usually carries it on the head because of weight). When the other children (usually the older ones) start getting masuku from the basket on the head of the youngest person and eat it, they abuse the child carrying the basket because she/he cannot get some to eat like her/ his other peers are doing because of the load on his/her head. But, when they reach home, masuku are shared equally regardless of the fact that others have already eaten some of their share. In this way, the younger child who carried the basket is seen to be treated unfairly because, firstly, she/he carried a heavy thing instead of an elderly child carrying it and, secondly, her/his share of masuku is also shared with others who have already eaten their share. So, the children lacked this sociocultural knowledge for them to figuratively interpret the idiom. This shows that at fourteen years idiom acquisition is still taking place and mastery of idioms has not yet been achieved, although the child's knowledge of idiomatic meaning starts resembling that of adults. This corroborates the findings of Karuppali and Bhat (2013) who found that fourteen-year-olds could not achieve 100\% accuracy in the figurative interpretation of idioms even though they are able to interpret most idioms figuratively. Our findings also show that nine-year-olds selected more 'literal' responses than any other age group in all three experiments. This suggests that nine years is a transitional age in idiom acquisition. It is the age at which a child is able to look for contextual information, both linguistic and sociocultural, in order to understand the idiom's meaning. However, the awareness of sociocultural information is still developing at this age. As a result, the children find it difficult to relate the linguistic information to the sociocultural information which sometimes is not even available to them. But, because at this age the children have acquired sensitivity towards the contextual information (Levorato 1993; Levorato and Cacciari 2002), they always search for linguistic information to deduce the meaning of the idiom. Thus, nine-yearolds ended up providing more literal answers because they were the most plausible. This can be illustrated by galu wakuda ('black dog' = famine), one of the idioms that was literally interpreted by nine-year-olds in the story context. The nine-year-olds realised that the 'filler' answer was not appropriate in the provided linguistic context but they could not recognise the sociocultural context within which the idiom is consumed. Thus, the idiomatic answer could not make sense in the provided linguistic context and they ended up selecting a literal answer as it was the safest answer. For these children to correctly interpret the idiom, they needed to know the visual problems that people experience due to severe hunger. People fail to see properly because of low sugar levels, dehydration and vitamin A deficiency. As a result, everything looks like a dark looking object that is not identifiable. Since most Malawian homes have tame dogs, it is assumed that the unidentified dark object seen by the person with the deficient eyesight is a dog black in colour. Because this unidentified object, wrongly identified as a black dog, is seen when people have nothing to eat during famine, it is believed that this 'black dog' is what mysteriously eats all the food, leaving people with nothing to eat. Hence, famine is referred to as galu wakuda (literally, a black dog). The nine-year-olds lacked this sociocultural knowledge. As a result, they had no choice but to select the literal answer which seemed more plausible in the provided context than either the filler answer or the idiomatic answer. However, the fourteen-year-olds did not select any literal responses in the story context. 
This suggests that fourteen-year-olds have developed an advanced awareness of the sociocultural context within which idioms are used.

The findings of this study also showed that idiomatic responses increase with age. This suggests that as children grow older they abandon the non-idiomatic responses. This is consistent with the findings in the studies by Prinz (1983), Laval (2003), Levorato, Nesi and Cacciari (2004), Hsieh and Hsu (2010), Vulchanova et al. (2011) and Karuppali and Bhat (2013). Based on the findings presented above, it can be argued that as children grow older, their knowledge of the sociocultural context within which idioms are consumed increases. As a result, they are able to deduce the dimensions that are really being talked about. This explains why there is an increased idiomatic response among the older children.

\section{Conclusion}

In this paper, we observed that although our results indicate that linguistically supportive contexts facilitate the interpretation and acquisition of idioms among children, it is not enough to facilitate children's interpretation and acquisition of idiomatic expressions. Children can have skills to use the contextual cues to deduce the meaning of an idiom, but they can still fail to idiomatically interpret the idiom if they lack knowledge of the sociocultural context in which the idiom was produced and is supposed to be consumed. Thus, we argue that idioms are texts produced within a specific sociocultural context and that the sociocultural context within which the idioms were produced is central to the interpretation and acquisition of the idiomatic expressions. As such, teachers should help learners to understand the sociocultural context within which the idioms are produced and consumed.

We also established in this paper that idiom acquisition starts with idiom recognition as an instance of use at around the age of four years and that actual idiomatic interpretation starts at around the age of six years when the child starts to develop the awareness of the cultural frames of reference and meaning guiding the use of idiomatic expressions. The knowledge of the cultural frames of reference increases as the children grow older. As a result, children's knowledge of idiomatic meaning starts resembling that of adults by the age of 14 years although at this age idiom acquisition is still taking place and mastery of idioms has not yet been achieved. On the basis of these findings, we argue that children come to know an idiomatic expression as a text before they even understand the sociocultural context in which it is produced and consumed. We also argue that idioms are acquired as texts and they are acquired together with the sociocultural context in which they are produced and consumed, and the sociocultural context forms part of the idioms. Therefore, idioms can only be interpreted and acquired within the sociocultural context in which they are produced and consumed. If idioms as texts are separated from the sociocultural context in which they were produced, they cannot be interpreted or acquired. This has implications for how idioms should be taught. Teachers should be aware of the sociocultural contexts within which idioms were produced, and they should explain such information to their learners. Such information will help the learners to easily acquire and use the idioms. Furthermore, we argue that there is a correlation between age and idiom interpretation and acquisition. As the child grows older, knowledge of the sociocultural context in which idioms are consumed

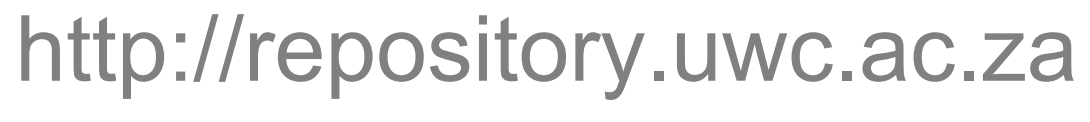


increases. As a result, non-idiomatic responses decrease as the children's age increases. Our results also show that nine years is a transitional age in idiom acquisition. It is the age at which a child is able to look for contextual information, both linguistic and sociocultural, in order to understand the idiom's meaning. However, the awareness of sociocultural information is still developing at this age. As a result, the children find it difficult to relate the linguistic information to the sociocultural information which sometimes is not even available to them. But, because at this age the children have acquired sensitivity towards the contextual information (Levorato 1993; Levorato and Cacciari 2002), they always search for linguistic information to deduce the meaning of the idiom. Our research is a first attempt to use SFL to investigate how children acquire the interpretation of Cicewa idiomatic expressions. Further research is necessary where a larger group of children of all ages, in the age range 4-14 years, are recruited to establish the transition that takes place in children when acquiring idioms. Furthermore, this study failed to establish the termination stage in idiomatic meaning acquisition because it did not recruit children above the age of 14. Thus, there is need to carry out a study that recruits children above 14 years to establish the termination stage in idiomatic meaning acquisition. 


\section{References}

Abkarian GG, Jones A, West G. 1992. Young children's idiom comprehension: Trying to get the picture. Journal of Speech and Hearing Research 35:580-587.

Abrahamsen EP, Smith R. 2000. Facilitating idiom acquisition in children with communication disorders: Computer vs Classroom. Child Language Teaching and Therapy 16: 227-239.

Ackerman BP. 1982. On comprehending idioms: Do the children get the picture? Journal of Experimental Child Psychology 33: 439-454.

C cciari C, Levorato MC. 1998. The effect of semantic analyzability of idioms in metalinguistic tasks. Metaphor and Symbol 13: 159-177.

Chunke Z. 2011. Measuring the impact of cultural context on Chinese ESL university learners' comprehension and memorization of figurative idioms. University essay, Kristianstad University, Sweden.

Eggins S. 2004. An introduction to systemic functional linguistics (2nd edn). New York and London: Continuum.

Fawcett R.P. 2008. Invitation to systemic functional linguistics: The Cardiff grammar as an extension and simplification of Halliday's systemic functional grammar (2nd edn). Cardiff: Centre for Language and Communication, Cardiff University.

Fazly A, Cook P, Stevenson S. 2009. Unsupervised type and token identification of idiomatic expressions. Computational Linguistics 35: 61-103.

Gallardo BC. 2006. Analysis of a literary work using systemic-functional grammar. In: Barbara L, Sardinha TB (eds), Proceedings of the $33^{\text {rd }}$ International Systemic Functional Congress, 10-15 July, Catholic University of São Paulo, São Paulo, Brazil. São Paulo: Applied Linguistics Graduate Program. pp 735-762.

Gibbs RW. 1987. Linguistic factors in children's understanding of idioms. Journal of Child Language 14: 569-586.

Gibbs RW. 1991. Semantic analyzability in children's understanding of idioms. Journal of Speech and Hearing Research 34: 613-620.

Graber PL. 2001. Context in text: A systemic functional analysis of the Parable of the Sower. Unpublished PhD thesis, Department of New Testament Graduate Division of Religion, Emory University.

Halliday MAK. 1978. Language as social semiotic. London and Baltimore: Edward Arnold. Halliday MAK. 1985. An introduction to functional grammar. London: Edward Arnold.

Halliday MAK. 2009a. Methods-techniques-problems. In: Halliday MAK, Webster JJ (eds), Continuum companion to systemic functional linguistics. New York and London: Continuum. pp 59-86.

Halliday MAK. 2009b. The essential Halliday. Webster JJ (ed). New York and London: Continuum.

Halliday MAK, Hasan R. 1989. Language, context and text: Aspects of language in a socialsemiotic perspective. Oxford: Oxford University Press.

Haratyan F. 2011. Halliday's SFL and social meaning. In: International Proceedings of Economics Development and Research (IPEDR) 17, 2nd International Conference on 
Humanities, Historical and Social Sciences, 21-23 October, Cairo, Egypt. IACSIT Press: Singapore. pp 260-264.

Hasan R. 2009. The place of context in a systemic functional model. In Halliday MAK, Webster JJ (eds), Continuum companion to systemic functional linguistics. New York and London: Continuum. pp 166-189.

Hsieh SC, Hsu CN. 2010. Idiom comprehension in Mandarin-speaking children. Journal of Psycholinguistic Research 39: 505-522.

Huber-Okrainee J, Blaser SE, Dennis M. 2005. Idiom comprehension deficits in relation to corpus callosum agenesis and hypoplasia in children with spina bifida meningomyelocele. Brain and Language 93: 349-368.

Janyan A, Andonova E. 2000. The role of mental imagery in understanding unknown idioms. In: Lila R. Gleitman LR, Joshi AK (eds), Proceedings of the 22nd Annual Conference of the Cognitive Science Society, 13-15 August, University of Pennsylvania, Philadelphia, PA. Mahwah, NJ: Lawrence Erlbaum Associates. pp 693-698.

Kamanga M. 2007. The semantics of Chichewa idioms: Towards an optimality theoretic account. Unpublished MA dissertation, University of Malawi, Malawi.

Kamanga 2012. In Kalua B (ed) University Research and Progress: Windows on Malawi. Proceedings of the University of Malawi, Chancellor College Research Conference. Blantyre: Assemblies of God Press. pp 267-284.

Karuppali S, Bhat J. 2013. Understanding of idiomatic expressions in children between 11-14 years. International Journal of English and Education 2: 1-10.

K mpler D, Van Lancker D, Marchman V, Bates E. 1999. Idiom comprehension in children and adults with unilateral damage. Developmental Neuropsychology 15: 327-349.

Laval V. 2003. Idiom comprehension and metapragmatic knowledge in French children. Journal of Pragmatics 35: 723-739.

Laval V, Bernicot J. 2002. Tue s dans la lune: Understanding idioms in French speaking children and adults. Pragmatics 12: 399-413.

Lavid J, Arús J, Zamorano-Mansilla JR. 2010. Systemic functional grammar of Spanish: A contrast study with English Volume 1. New York and London: Continuum

Leung TT. 2011. Effect of linguistic context and transparency on the comprehension of idioms in Cantonese-speaking children. Unpublished BSc dissertation, University of Hong Kong.

Levorato MC. 1993. The acquisition of idioms and development of figurative competence. In: Cacciari C, Tabossi P (eds), Idioms: Processing, structure and interpretation. Hillsdale, NJ: Laurence Erlbaum Associates. pp 105-128.

Levorato MC, Cacciari C. 1992. Children's comprehension and production of idioms: The role of context and familiarity. Journal of Child Language 19: 415-433.

Levorato MC, Cacciari C. 1995. The effects of different tasks on the comprehension and production of idioms in children. Journal of Experimental Child Psychology 60: 261283 .

Levorato MC, Cacciari C. 1999. Idiom comprehension in children: Are the effects of semantic analysability and context separable? European Journal of Cognitive Psychology 11: 51-66. 
Levorato MC, Cacciari C. 2002. The creation of new figurative expressions: Psycholinguistic evidence in Italian children, adolescents and adults. Journal of Child Language 29: 127-150.

Levorato MC, Nesi B, Cacciari C. 2004. Reading comprehension and understanding idiomatic expressions: A developmental study. Brain and Language 91: 303-314.

Levorato MC, Roch M, Nesi B. 2007. A longitudinal study of idiom and text comprehension. Journal of Child Language 34: 473-494.

Lirola MM. 2005. A systemic functional approximation to the use of cleft sentences and reversed pseudo-cleft sentences in English in a narrative sample written by the South African writer Alan Paton. Working Papers 10. Universidada De Alicante, Departamento de Filolagia Inglesa.

Lodge D, Leach E. 1975. Children's acquisition of idioms in the English language. Journal of Speech and Hearing Research 18: 521-529.

Martin J R. 1992. English text: System and structure. Philadelphia and Amsterdam: John Benjamins.

Martin JR. 2009. Discourse studies. In: Halliday MAK, Webster JJ (eds) Continuum companion to systemic functional linguistics. New York and London: Continuum. pp 154-165.

Martin JR, Rose D. 2003. Working with discourses: Meaning beyond the clause. London and New York: Continuum.

Matthiessen CMIM, Halliday MAK. 1997. Systemic functional grammar: A first step into the theory. Available online: http://minerva.ling.mq.edu.au/resource/VirtuallLibrary/Publications/sfg_firststep/ SFG\%20intro\%20New.html

Matthiessen CMIM, Teruya K, Lam M. 2010. Key terms in systemic functional linguistics. New York and London: Continuum.

Painter C. 2000. Researching first language development in children. In: Unsworth L (ed), Researching Language in Schools and Communities: Functional Linguistic Perspective. London and Washington: Cassell. pp 65-86.

Painter C. 2009. Language development. In: Halliday MAK, Webster JJ (eds) Continuum companion to systemic functional linguistics. New York and London: Continuum. pp 87-103.

Prinz PM. 1983. The development of idiomatic meaning in children. Language Speech 26: 263-272. Riehemann S. 2001. A constructional approach to idioms and word formation. Unpublished PhD Dissertation, Stanford University, USA.

Schnell Z. 2007. Metaphor processing and the acquisition of idioms: A mentalistic model. Acta Linguistica Hungarica 54: 73-104.

Schweigert WA, Cronk BC. 1992/93. Ratings of the familiarity of idioms' figurative meanings and the likelihood of literal meanings among U.S. college students. Current Psychology 11: 323-345.

Strand K, Fraser B. 1979. The comprehension of verbal idioms by young children. Paper presented at the Boston University language development conference, 14-15 September 1979, George Sherman Union, Commonwealth Avenue, Boston. Boston University School of Education: Boston. 
Teich E. 1999. Systemic functional grammar in natural language generation: Linguistic description and computational representation. London and New York: Cassell.

Thyab RA. 2016. The necessity of idiomatic expressions to English language learners. International Journal of English and Literature 7(7):106-111.

Titone DA, Connine CM. 1994. Descriptive norms for 171 idiomatic expressions: Familiarity, compositionality, predictability, and literality. Metaphor \& Symbol 9(4): 247-270.

Vicker B. 2002. Building competency with figurative language one idiom at a time. BBB Autism; Printable article \#62. Accessed at http://www.bbbautism.com/pdf/article 62 buildingempetency wit hefigurative language

Vulchanova M, Vulchanov V, Stankova M. 2011. Idiom comprehension in the first language: A developmental study. Vigo International Journal of Applied Linguistics 8: 207-234.

Wattles I, Radić Bojanić B. 2007. The analysis of an online debate: The systemic functional grammar approach. Linguistics and Literature 5: 47-58. 